\title{
O INCENTIVO À LEITURA NA EDUCAÇÃO BÁSICA, A PARTIR DO PNBE
}

\author{
Darlaine Pereira Bomfim das Mercês ${ }^{1}$ \\ Universidade Federal da Bahia
}

Barbara Coelho Neves ${ }^{2}$

Universidade Federal da Bahia

Márcea Andrade Sales ${ }^{3}$

Universidade do Estado da Bahia

\begin{abstract}
Resumo
Com o objetivo de problematizar a atuação do Programa Nacional Biblioteca da Escola (PNBE) enquanto uma política pública educacional de acesso ao livro que atua na Educação Básica, esta pesquisa foi realizada utilizando como dispositivo a pesquisa documental, a observação e a pesquisa bibliográfica. Teve a inserção e fundamentação no campo da etnografia escolar (André, 2008) em uma escola da rede pública estadual, localizada em Salvador. O estudo salienta a importância das políticas públicas educacionais, sendo fundamentado em Sousa (2006), Torres (2003) e Hofling (2001). A discussão sobre leitura na Educação Básica está amparada em Kleiman (2008), Lajolo (2002), Pereira (2012), Oliveira e Tomazetti (2012) e Abu-El-Haj (2013). As estratégias para intervenção no campo estiveram alicerçadas em Braga e Silvestre (2002) e Hooks (2013). No primeiro momento, em 2016, os sujeitos da pesquisa foram os estudantes do último ano do Ensino Médio desta escola, quando foram realizadas rodas de leitura dentro da biblioteca, contudo, os participantes se restringiram àqueles que já concebiam a leitura como um hábito. Isto posto, em 2018, as rodas de leitura foram desenvolvidas com estudantes do primeiro ano do Ensino Médio, em sala de aula, com intuito de possibilitar novas experiências de prática de leitura do mundo, a partir dos conteúdos programáticos da Sociologia; e aproximá-los do acervo de livros disponibilizados pelo PNBE que estão disponilizados na biblioteca da escola.
\end{abstract}

Palavras-chave: Incentivo à leitura. PNBE. Políticas Públicas Educacionais.

\section{ENCOURAGING READING IN BASIC EDUCATION, FROM PNBE}

\begin{abstract}
In order to problematize the performance of the National School Library Program (PNBE), as an educational public policy of access to the book that acts in Basic Education, this research was used as a device for documentary research, observation and bibliographic research. It had an insertion and foundation in the field of school ethnography (André, 2008) in a school of the state public network, located in Salvador. The study highlights the importance of educational public policies, based on Sousa (2006), Torres (2003) and Hofling (2001). The discussions about reading in Basic Education are related in Kleiman (2008), Lajolo (2002), Pereira (2012), Oliveira and Tomazetti (2012) and Abu-El-Haj (2013). Strategies for field intervention are located in Braga and Silvestre

\footnotetext{
${ }^{1}$ Mestranda do Programa de Pós-Graduação em Educação.

${ }^{2}$ Professora do Programa de Pós-Graduação em Educação e do Programa de Pós-Graduação em Educação. Líder do Laboratório de Tecnologias Informacionais e Inclusão Sociodigital (LTI Digital). Pós-Doutora em Ciência da Informação. Doutora em Educação. Mestre em Ciência da Informação.

${ }^{3}$ Pós Doutorado em Educação. Universidade Federal de Uberlândia (2017). Doutora em Educação (2009). Universidade Federal da Bahia - Faculdade de Educação - FACED UFBA. Professora Titular da Universidade do Estado da Bahia - Departamento de Educação. Campus I/Salvador. Professora Permanente do Mestrado em Gestão e Tecnologias Aplicadas à Educação - GESTEC UNEB.
}

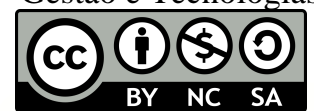


(2002) and Hooks (2013). At first, in 2016, the research subjects were the students of the last year of high school of this school, when the reading wheels were held inside the library, but the participants were restricted to the tracks that were already read as a habit. This post, in 2018, as the reading wheels were held with the students of the first year of high school, in the classroom, with the possibility of new experiences of reading practice in the world, from the syllabus syllabus; and bring them closer to the collection of books made available by PNBE that are available in the school library.

Keywords: Reading incentive. PNBE. Educational Public Policies.

\section{INTRODUÇÃO}

A $3^{\text {a }}$ edição da Pesquisa Retratos da Leitura no Brasil (2011) indica que $28 \%$ dos entrevistados têm a leitura como atividade realizada no tempo vago com média de 1,85 livros lidos nos últimos três meses. Em 2016, na $4^{\text {a }}$ edição da mesma Pesquisa, os resultados divulgados indicam a escola como principal mediador do acesso aos livros, pois $27 \%$ dos entrevistados têm a escola como espaço de contato com os livros e a leitura - especificamente, $18 \%$ afirmam que os livros lidos são oriundos de empréstimo nas bibliotecas escolares como principal forma de acesso, e 9\% têm os livros distribuídos pelo governo ou pelas escolas.

Nesse contexto, apresentamos, aqui, uma pesquisa sobre políticas públicas nacionais de incentivo à leitura na Educação Básica, realizada com financiamento oriundo de editais de Iniciação Científica promovidos em uma universidade pública baiana (entre 2013 e 2018), resultando no Trabalho de Conclusão de Curso apresentado em 2016 e reverberando no atual projeto de pesquisa do mestrado no Programa de Pós-Graduação em Educação, stricto sensu.

Evidenciaremos alguns resultados de pesquisas anteriores para realização deste estudo descritivo, de caráter qualitativo, realizado através de levantamento documental e bibliográfico, com o apoio da etnografia escolar (ANDRÉ, 2008) como método de pesquisa de campo. Foi adotado como estratégia, junto aos sujeitos da pesquisa, rodas de leitura na biblioteca escolar com os estudantes do último ano do Ensino Médio no ano de 2016 - e, dentro da sala de aula durante as aulas de Sociologia - em uma turma do primeiro ano do Ensino Médio em 2018 - em uma escola da rede pública estadual de Salvador. Apresentaremos, especificamente, a atuação do Programa Nacional Biblioteca da Escola (PNBE) - uma política pública de acesso à leitura na Educação Básica -, bem como as estratégias desenvolvidas para mediação da leitura - na biblioteca escolar e em sala de aula -; com ênfase na discussão sobre o papel das políticas públicas educacionais em tempos de neoliberalismo - um dos objetivos da pesquisa na PósGraduação (em andamento); pois acreditamos que as políticas públicas educacionais expressam o papel da educação na sociedade (FARENZENA, 2014). 


\section{O PNBE COMO UMA POLÍTICA PÚBLICA EDUCACIONAL}

A educação como um direito de todos foi um dos postulados da Declaração Universal dos Direitos Humanos. Desde então, segundo Claude (2005, p.40) a “(...) educação é direito social, um bem social e uma responsabilidade da sociedade como um todo." Reafirmado pela Declaração Mundial de Educação para Todos - Documento da Conferência de Jomtien, 1990 este direito tem sido concretizado através de Políticas Públicas apresentadas à sociedade como as ações governamentais traduzido nas “(...) plataformas eleitorais em programas e ações que produzirão resultados ou mudanças no mundo real.” (SOUZA, 2006, p.26). Contudo, em tempos de forte presença das políticas neoliberais, vislumbramos uma lacuna entre a utilização da política que vem sendo atribuída a uma crise gerencial das escolas da rede pública (GENTILI, 1996).

Enquanto um direito social as Políticas Públicas Educacionais, segundo Torres (2003), devem reivindicar a equidade. Contudo, devido a profunda estatização (GENTILI, 1996), as políticas educacionais tem ressaltado a pobreza, os privilégios das minorias e, consequentemente, a desigualdade. Em meio ao “(...) discurso da democratização do ensino público e a elevação da sua qualidade baseados nos princípios da justiça social e equidade (...)" (DAYRELL, 2007, p. 1123), o que encontramos no cotidiano escolar são leituras dirigidas e limitadas que não resolvem a crise da leitura (LAJOLO, 2002). Afinal, a leitura no Ensino Médio tem como finalidade “(...) ampliar a consciência crítica, promover um cidadão atuante na sociedade e despertá-lo para reflexões importantes sobre o mundo que os cerca." (PEREIRA, 2012, p.38).

Dito isto, nos opomos ao que alguns pesquisadores chamam de crise da leitura. Acreditamos, assim como Silva (2003), que o acesso ao livro, por ser um ato de conhecimento, tem sido elitizado desde o período colonial, refletindo significativamente na qualidade da educação na rede pública brasileira até a contemporaneidade, já que o aprendizado das demais disciplinas escolares perpassam pela leitura e interpretação de textos, explicações ou questões. Não obstante, a partir de 1990, políticas de incentivo à leitura começaram a ser implantadas em todo o país; e, em 1997, foi implantado o PNBE com o intuito de promover o acesso à cultura através da leitura, distribuindo acervos compostos por obras de pesquisa, referência e literatura para todas as escolas públicas cadastradas no Censo Escolar.

O Programa Nacional Biblioteca da Escola (PNBE) é um dos Programas que integram o Fundo Nacional de Desenvolvimento da Educação (FNDE). Este Fundo foi instituído pela Lei n ${ }^{\circ} 5.537$ de 1968 para abrigar a execução de programas cujos objetivos estão relacionados 
a melhorias na estrutura escolar, incluindo os livros através de programas como Programa Nacional do Livro Didático (PNLD), o Programa Nacional do Livro para o Ensino Médio (PNLEM), entre outros. Para Ala-Harja e Helgason (apud CUNHA, 2003, p. 07), os Programas são,

[...] um conjunto de atividades organizadas para serem realizadas dentro de cronograma e orçamento específicos disponíveis para a implementação de políticas, ou para a criação de condições que permitam o alcance de metas políticas desejáveis.

O PNBE foi instituído pela Portaria Ministerial n 584, 28 de abril de 1997, objetivando “(...) promover o acesso à cultura e o incentivo à leitura nos alunos e professores por meio da distribuição de acervos de obras de literatura, de pesquisa e de referência" (BRASIL, 1997). Para isso, atualmente, o Programa atende a todas as escolas públicas cadastradas no Censo Escolar realizado pelo Instituto Nacional de Estudos e Pesquisas Educacionais Anísio Teixeira (INEP) .

Embora, desde o princípio, o PNBE tenha distribuído livros de forma sistemática para as escolas da rede pública, a partir do ano 2000, percebendo o déficit na formação docente (no que tange a capacitação para mediação da formação do hábito de leitura), elabora e distribui obras direcionadas aos professores do Ensino Fundamental das escolas públicas participantes do Programa de Desenvolvimento Profissional Continuado - Programa Parâmetros em Ação , para tentar sanar este problema. Contudo, ainda cabe indagar sobre a efetividade deste eixo do Programa, pois a observação realizada durante a pesquisa etnográfica, realizada na Biblioteca da Escola pesquisada, os materiais direcionados aos professores revelam ter pouco uso - revistas em bom estado, sem dobras ou amassados, Dvd's embalados no plástico de vedação, por exemplo. Isso não quer dizer que os docentes não tenham interesse em formação continuada; mas, talvez, a estratégia de uso e distribuição de material não seja a mais eficaz.

Outra ação direcionada do PNBE foi a distribuição direta de livros paradidáticos para os estudantes da rede pública que cursavam a Educação Básica, entre 2001 e 2003, através da ação "Literatura em Minha Casa". Em 2003 houve outras ações que tinham a mesma forma de operação, mas contemplando outros públicos; para Educação de Jovens e Adultos (EJA) houve o "Palavra da Gente" e a "Casa da Leitura" que foi a distribuição de bibliotecas itinerantes para uso municipal - esta ação contou com parcerias com secretarias estaduais e municipais de educação. Neste mesmo ano, o Programa distribuiu 144 títulos a mais para as escolas com maior número de alunos.

Em 2007 este Programa foi ampliado e começou a atender escolas do Ensino Médio e da Educação Infantil - por dez anos contemplou, apenas, as escolas do Ensino Fundamental. 
No entanto, não foi objeto da pesquisa, aqui referenciada, investigar os valores investidos, nem o número de escolas contempladas; e sim o incentivo à leitura na Educação Básica e como os materiais do PNBE têm auxiliado à prática de leitura dos estudantes.

Desde a $2^{\text {a }}$ edição $(2007,2011$ e 2015) a pesquisa Retratos da Leitura no Brasil aponta que a quantidade de livros (inteiros ou em partes) lidos anualmente pelos entrevistados cresce no mesmo sentido que renda familiar, ou seja, "(...) quanto mais se ascende na hierarquia social, mais aumenta o número de livros lidos" (Horellou-Lafarge e Segré, 2010, p. 105), trazendo o recorte de classe para esta pesquisa. Segundo, Maués (2002) a desigualdade social que assola o país é fielmente reproduzida no campo da leitura; mas alguns estudantes, que a autora chama de heróicos, conseguem superar o problema do acesso através do empréstimo de livros com amigos ou em bibliotecas e sendo tais estudantes os sujeitos da pesquisa.

Neste sentido, as políticas públicas de acesso ao livro didático e paradidático atuam em esferas que possibilitam o acesso destes estudantes heróicos aos livros. Partindo da premissa que as ações de incentivo à leitura são implantadas através de Planos e Programas, eles se complementam ao atuar em diferentes campos como Bibliotecas escolares e rurais, formação de mediadores, distribuição de livros didáticos, segundo Mercês (2016).

Tal ação ressalta uma das características apontadas por Hofling (2001) para políticas públicas: a regulação dos desequilíbrios e desigualdades sociais que resultam do sistema capitalista, nos governos neoliberais; pois, mesmo com a quantidade de dinheiro investida na educação e nos programas específicos para o incentivo à leitura não há concretude no problema do acesso.

Outrora, o problema brasileiro estava em torno da quantidade de crianças e adolescentes que não ingressaram no ambiente escolar ou que passaram sem concluir etapas, segundo Oliveira (2017). Na contemporaneidade, o pleito é pela qualidade, refutando o sentido (neo)conservador e (neo)liberal, logo:

\footnotetext{
"igualdade na qualidade recebida por todos os cidadãos e (...) abolição definitiva de qualquer tipo de diferenciação ou segregação social. (...) transformando a qualidade em um direito e não em uma mercadoria vendida ao que der a melhor oferta. A escola pública é o espaço onde se exercita este direito, não o mercado. (GENTILI, 2015, p. 176)"
}

Enguita apud Gentili (2015) dialogado sobre a subordinação da educação ao mercado aponta que para os filhos da classe trabalhadora qualquer educação serve. Em ressonância, neste cenário vivenciamos os livros chegando na escola, mas os estudantes não acessam-os, sequer conhecem o acervo disponível, por isso pensar estratégias que promovam a prática da leitura do mundo durante as aulas possibilitaria novas experiências de leitura, na tentativa de superar 
a negligência estrutural com a formação dos alunos que, hoje, ocupam as escolas da rede pública.

\section{O PNBE NA ESCOLA}

A biblioteca de um Colégio Estadual, em Salvador, foi o lócus inicial da pesquisa de Iniciação Científica - à época, o intuito era compreender a prática da formação do leitor na Educação Básica. Em 2015 e 2016 este espaço foi campo da pesquisa, sendo utilizado, como recurso metodológico, a observação do cotidiano da Biblioteca, na perspectiva da Etnografia escolar. Para André (2008, p. 27), antropologicamente, a etnografia é “(...) um conjunto de técnicas [...] para coletar dados sobre os valores, os hábitos, as crenças, as práticas e os comportamentos de um grupo social”.

Considerando o recebimento de materiais do PNBE e de outros Programas do FNDE, a Biblioteca da Escola pesquisada estava em ótimo estado e em pleno funcionamento. Além da boa estrutura física seu acervo de livros é variado, possuindo mais de um exemplar do mesmo livro - exceto dos livros que foram doados; no espaço há, também, Revistas e DVD’s distribuídos pelo FNDE para uso docente.

O uso da etnografia como recurso metodológico possibilitou articulação singular entre o campo e a pesquisa. Assim, no decorrer da prática etnográfica, além de conhecer os funcionários, os frequentadores e o acervo, foram mapeadas atividades realizadas pela gestão, pelos docentes; bem como pelo setor, sendo identificada a necessidade/possibilidade de realização de atividade de prática de leitura com os estudantes.

Cogitamos $^{4}$, inicialmente, realizar oficinas com todos os frequentadores da Biblioteca, no turno vespertino. Mas, considerando a necessidade de possibilitar novas experiências de leitura com os estudantes, e atentas ao que nos diz Kleiman (2008, p. 16) que, “(...) para a maioria, as primeiras lembranças dessa atividade são a cópia maçante, até a mão doer (...)", decidimos por limitar o público alvo aos estudantes das turmas de $3^{\circ}$ ano do Ensino Médio pela iminência de concluir a Educação Básica, sem experiências de prática de leitura contrárias às lembranças acima mencionadas.

Considerando o diálogo fomentado por Rodas de Leitura, utilizamos-as como estratégia para propiciar a reinterpretação/ressignificação do que foi entendido na leitura realizada

\footnotetext{
${ }^{4} \mathrm{O}$ plural, aqui, inclui, também, integrantes do Grupo de Pesquisa GEFEP UNEB/CNPq - a partir da escuta às estratégias e formatos para a pesquisa propostos, neste coletivo.
} 
individualmente, possibilitando aos alunos identificarem as diversas percepções sobre o mesmo material a partir das particularidades de cada indivíduo; já que, a prática de leitura se dá pela "leitura e interpretação, reinterpretando e agindo sobre o texto lido e que acontece a efetivação da criticidade mental do aluno" (PEREIRA, 2012, p.17).

\section{RODAS DE LEITURA A PARTIR DO PNBE}

O livro escolhido para abrir a Roda ${ }^{5}$ foi Triste Fim de Policarpo Quaresma de Lima Barreto - publicado em 1911 como Folhetim, e no formato livro, em 1915. A escolha da obra se deu por ser um dos títulos com grande quantidade de exemplares na Biblioteca da Escola (17 unidades), pelas possíveis intertextualidades e as semelhanças entre o contexto político da obra e da realização da atividade; além da citação de trechos da obra em versões anteriores do Exame Nacional do Ensino Médio (Enem).

A participação na Oficina aconteceu por adesão dos estudantes, ou seja, participaram àqueles que se sentiram instigados a fazer a atividade, pois o intuito desta foi promover e/ou consolidar o hábito de leitura dos estudantes. Dessa forma, tivemos uma participação significativa, apesar de flutuante no número de estudantes a cada encontro - mínimo de 03 , máximo de 17 estudantes.

No que concerne a metodologia, a estratégia foi fundamentada em Braga e Silvestre (2002), organizando-a em três etapas: Pré-Leitura, Leitura Descoberta e Pós-Leitura. A PréLeitura, foi realizada durante passagens nas turmas do $3^{\circ}$ ano, ocasião em que foi realizado o que chamamos de 'Degustação'. Neste momento foram apresentados trechos da obra e possíveis reflexões a respeito, o motivo da escolha da obra, características do Modernismo (situando-os na Escola Literária que a obra está vinculada), pontuando aspectos atuais da obra para argumentar sobre a possibilidade da mesma ser utilizada no Enem 2016. Explicamos a metodologia das rodas de leitura e foi solicitada a leitura do livro em casa para que nos encontros não precisássemos realizar a leitura da obra na íntegra. Neste momento em algumas turmas começaram as interações, pois a professora de Língua Portuguesa havia trabalhado o Modernismo há pouco tempo, e falado sobre o livro como um dos mais conhecidos do PréModernismo, havendo diálogo sobre o personagem Policarpo - alguns apontaram que ele foi um herói, outros diziam que era louco, etc.

\footnotetext{
5 Cabe enfatizar que o livro foi, apenas, o estopim das discussões que perpassaram por diversos temas, a partir da leitura realizada.
} 
A Leitura-Descoberta foi realizada individualmente pelos participantes para respeitar as particularidades dos hábitos e ritmos para compreensão da leitura, como apontam Braga e Silvestre (2002). Os estudantes, durante a Degustação, foram orientados a realizarem o empréstimo do livro na Biblioteca e lerem, pelo menos, os primeiros capítulos para que, durante as Rodas, dialogassem sobre a leitura realizada. Nesta etapa das Rodas de Leitura o PNBE foi fundamental porque, devido a distribuição de livros feita pelo Programa, os estudantes tiveram a possibilidade de fazer o empréstimo do livro na Biblioteca da Escola e, por conseguinte, a realização da leitura.

As Rodas de Leitura corresponderam à Pós-Leitura. Nos encontros para leitura coletiva foram priorizadas as interpretações e reflexões da Leitura-Descoberta. O diálogo foi incitado através de outros recursos de mídia como músicas e filmes ${ }^{6}$. Por terem realizado, efetivamente, a leitura-descoberta, individualmente, durante os encontros observarmos o contexto histórico, social, político, econômico e cultural da obra literária; houve, também, a participação dos estudantes no exercício da mediação ao trazerem trechos do livros de história para relacionarmos com a obra e vídeos do Youtube que mencionam a época.

Como dito anteriormente, quantitativamente, as Rodas contaram com dois participantes fixos e variação entre 3 e 17 participantes. No entanto, qualitativamente, foi marcada pelo diálogo entre 3 participantes sobre a intencionalidade de Lima Barreto de tratar de alguns aspectos como o misticismo e o saber popular - uma discussão pautada no trecho em que o personagem 'Policarpo Quaresma' está no interior e teme prever a plantação; pois, cientificamente, não havia indícios de chuva, mas uma mulher com saber popular o contrapõe falando que choverá e chove. Logo, as Rodas de Leitura possibilitaram aos estudantes que não estavam familiarizados com a leitura participassem dos encontros e dialogassem - momentos de grande interação entre a obra literária e seus leitores.

Os participantes divulgavam as Rodas entre seus pares - nos encontros sempre tinham alguns participantes que estavam ali porque outro havia comentado sobre a atividade - a qual ganhou certa notoriedade pois a Direção informou à Secretaria de Educação do Estado SEC/BA sobre ela, e o órgão enviou uma equipe para fazer reportagem com estudantes participantes. Neste sentido, não podemos deixar de registrar a importância da participação da Escola parceira ao acolher atividades de pesquisa e seus desdobramentos na unidade escolar.

\footnotetext{
${ }^{6}$ Assistimos ao filme baseado na obra literária, na íntegra, Policarpo Quaresma, Herói do Brasil e trechos de Mauá - o Imperador e o Rei para observação de características do contexto da obra de Lima Barreto que estava sendo estudada.
} 
Em paralelo, cabe registrar que apenas estudantes que já tinham o hábito de leitura, ou o teve, em algum momento, participaram dos encontros exercitando a leitura além da decodificação.

\section{ESTRATÉGIAS DE LEITURA DO MUNDO, EM SALA DE AULA}

TTendo em vista a percepção da falta de acesso aos materiais fornecidos pelo PNBE durante o exercício etnográfico, e que o acesso as rodas de leituras realizadas na biblioteca não alcançaram massivamente os estudantes, a pesquisa seguiu na mesma Escola em 2018, agora articulada ao Estágio Curricular Supervisionado, na Licenciatura em Ciências Sociais. Neste momento, foram realizadas novas Rodas de Leitura, agora, com estudantes do primeiro ano do Ensino Médio, e em sala de aula, para possibilitar experiências de leitura na contramão da leitura cansativa e massante KLEIMAN, 2008) que integra o cotidiano escolar - uma proposta ancorada na concepção de leitura do mundo, a partir do conteúdo programático da Sociologia.

A formação de leitores na Educação Básica é objeto de estudo para diversas pesquisadoras como Abu-El-Haj (2013), Kleiman (2008), Terzia (2002), Braga e Silvestre (2002). As discussões realizadas estão sendo consideradas nas avaliações que, atualmente, objetivam examinar a capacidade de leitura e interpretação. Neste sentido o PISA, por exemplo, avalia os estudantes a partir do letramento em leitura, compreendido "como um conjunto crescente de conhecimentos, habilidades e estratégias que as pessoas constroem durante a vida em diversos contextos, por meio da interação com seus pares e com a comunidade em geral." (Brasil, 2016, p. 92). Logo, a leitura é a construção de significados do texto, como uma reação e na avaliação pretende medir o "conhecimento de mundo" (Brasil, 2016, p. 92). Este conhecimento do mundo é o que Lajolo (2002, p. 26) chama de leitura do mundo capaz de gerar “(...) comportamentos, sentimentos e atitudes (...)" quando as atividades de leitura buscam o significado mais amplo do texto.

Ainda neste campo de discussão Oliveira e Tomazetti (2010, p. 133) falam em segunda alfabetização e sustentam que, esta, “(...) torna o sujeito um cidadão capaz de ler as discrepâncias e contradições de nosso mundo globalizado (...)”. Para as autoras, tal aptidão deve ser praticada em diversas plataformas como no contato com uma produção cinematográfica americana ou um videoclipe no YouTube.

Mas, para isso, é necessário que os estudantes tenham,

(...) mais experiências com a leitura ele melhora sua percepção crítica, desde que seja uma leitura sistematizada que respeite fatores e saberes do educando que estimule sua própria autonomia, pois através da leitura o aluno adquire muito conhecimento e a partir dele que se construirá a sua própria opinião e criticidade, (...) (PEREIRA, 2012, p. 33) 
Em vista disso, as oficinas em Rodas de Leitura, realizadas em sala de aula, são/foram importantes para superar a ideia de leitura como atividade monótona de decodificação, experimentando a leitura do mundo e superando a prática de leitura “(...) dirigida, planejada, limitada no tempo e no espaço." (LAJOLO, 2002, p. 44) realizada na escola. Superam, também, leituras maçantes e cansativas, descritas por Kleiman (2008).

Destacamos estes aspectos, pois as práticas descritas pelas autoras em seus supracitados estudos embargam o desenvolvimento pessoal e coletivo no que tange ao aprendizado ao longo da vida preconizado por Delors (1998) ao não corroborar com a concepção de aprender a aprender e não formar “(...) a capacidade de julgar.” (idem, p. 47).

Isto posto, compreendendo que a leitura não é restrita a palavras escritas, estrategicamente, as Rodas de Leitura contaram com charges e cartuns como pré-textos para o diálogo, selecionadas a partir do conteúdo programático - Política, Estado e Sociedade -, e da discussão observada durante as aulas da professora regente. Ficou explícita a dificuldade dos estudantes se perceberem enquanto sujeitos que praticam ações políticas.

Na primeira Roda colocamos as carteiras em círculo, explicando a importância de ver e ouvir a todos, horizontalmente, pois a leitura e a fala partem da relação entre o que está sendo lido e nossas experiências e a importância de ouvir com atenção as narrativas dos colegas porque todas as falas são importantes para construção do conhecimento. Afinal, todos os presentes vivenciam experiências e estão aptos a ler, interpretar, falar e ser ouvido, criando uma “(...) comunidade de aprendizado onde a voz de cada um possa ser ouvida, a presença de cada um possa ser reconhecida e valorizada" (Hooks ${ }^{7}, 2013$, p. 245) propiciando a consciência uns dos outros através do reconhecimento da singularidade de cada fala/voz/interpretação.

Para Daryell (2007, p. 1119), “Os jovens pobres estão, cada vez mais, transpondo os seus muros, trazendo suas experiências e novos desafios.”. Nas Rodas não ocorreram o óbvio, pois os estudantes ao escutarem falar sobre elas, acreditaram que levaríamos livros coletivamente. Assim foi argumentado que leitura não é só de livro; naquele momento seriam lidas imagens, começando pela charge a seguir.

\footnotetext{
${ }^{7}$ A grafia do nome da autora em minúsculo se dá por ela negar o protagonismo do engajamento, rejeitando o uso de maiúsculas. Sua recomendação é seguida, aqui,, grafando seu nome em minúsculo.
} 
Figura 1. Charge 1, usada para discussão em sala

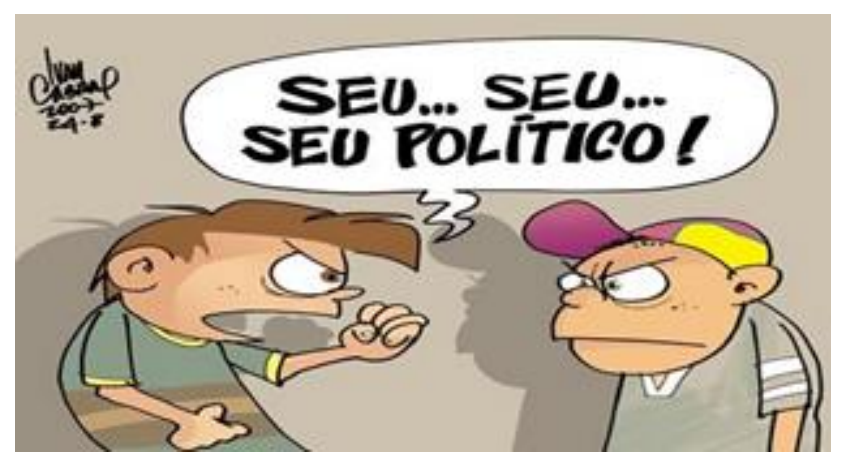

Fonte:Toluna (2019)

Nota: https://br.toluna.com/polls/6886374/xingamentos-ditados-mais-peculiares-de-uma-forma-mais

Por que político aparece como um xingamento na charge? Esta foi a provocação inicial e as respostas convergiram: todo político rouba, então chamar a pessoa de política quer dizer que ela é ruim. Após os apontamentos realizados sobre o que eles concebem como política (citaram roubo, corrupção, desvio de dinheiro, entre outros), expliquei que estes são os desvios e todos nós realizamos ações políticas. Esta escuta às respostas é/foi importante, pois “[...] muitos aspectos que o aluno sequer percebeu ficam salientados nessa conversa, muitos pontos que ficaram obscuros são iluminados na construção conjunta da compreensão" (Kleiman, 2008, p.24).

Observando o espanto da maioria, Max Weber foi apresentado à discussão com as três formas de dominação: dominação carismática, tradicional e racional. Em seguida foi solicitado que eles relacionassem esta teoria à escolha do seu voto para líder de classe. Neste momento a maior parte da sala interagiu, falando sobre seu voto a partir da teoria weberiana e justificando com ações do líder eleito observadas por seus pares/eleitores, ou seja, eles superaram a leitura automatizada (Kleiman, 2008) que se concretiza, apenas, com a decodificação de conceitos teóricos.

Nos encontros seguintes, os estudantes começaram a expor suas opiniões políticas, trazendo seus posicionamentos, votos dos familiares e fazendo relação com as formas de dominação teorizadas por Weber. Em seguida dialogamos sobre o poder de manipulação e como "a negação da política é importante para que os votos e posicionamentos não sejam racionais" (fala de um dos estudantes no final da roda de leitura), evidenciando que o diálogo resultou “(...) na construção, difusão e alteração de sensibilidades (...)” (Lajolo, 2002, p.26), ou seja, o exercício de leitura coletiva com a livre interpretação suscitou comportamentos, sentimentos e atitudes quanto à compreensão e leitura sobre si enquanto sujeito político. 
Provocando-os a pensarem sobre o objetivo da pesquisa, uma outra roda de leitura tinha a seguinte imagem como último material:

Figura 2. Charge 2, usada para discussão em sala

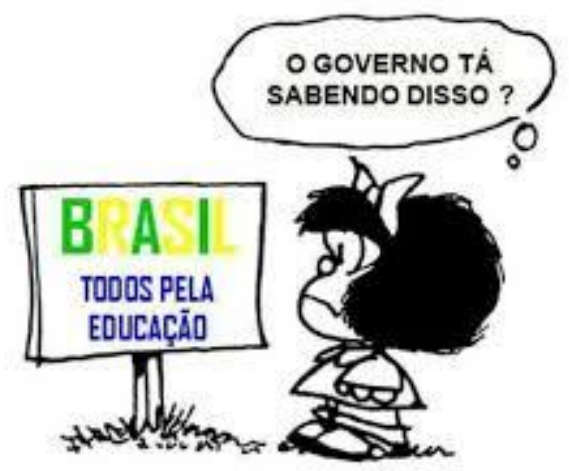

Fonte: Formulageo (2018)

Nota: http://formulageo.blogspot.com/2012/09/mafalda-em-brasil-todos-pela-educacao-o.html

Com esta a imagem a proposta foi explicar para os estudantes sobre o PNBE, a história, as ações, o acervo na Biblioteca da Escola, muitas vezes sem ser acessado por desconhecimento - poucos atentam para a diversidade de gêneros literários e tipos de livros naquele espaço. Por fim, propor que eles visitassem o espaço para contribuírem para efetivação de uma política pública educacional, afinal ela é uma conquista, uma ação governamental em prol da afirmação do direito social à educação.

\section{CONSIDERAÇÕES (NÃO TÃO) FINAIS}

Os espaços escolares ainda padecem com políticas educacionais equivocadas como as voltadas para a leitura/livro, por disseminar o acesso à livros que são subutilizados nas bibliotecas escolares e nas salas de aula (Mercês, 2016), pois os estudantes na Educação Básica costumam ter contato efetivo, apenas, com livros didáticos, realizando leituras e atividades centradas no binarismo - certo ou errado -, sem o desenvolvimento e valorização das interpretações, concluindo a Educação Básica e sem “(...) a capacidade de atribuir sentido ao que é ensinado, condição essencial para a aprendizagem” (Dayrell, 2007, p. 1122), comprometendo seu desenvolvimento intelectual e profissional.

Abu-El-Haj (2013, p. 38), chama a atenção para “(...) conceitos de leitura compreensiva, leitura significativa, leitor ativo, interação leitora (...)” como novas diretrizes, e “(...) nas estratégias cognitivas e metacognitivas como ferramentas valiosas no ensino e na formação do 
sujeito leitor." Evidencia, também, as falhas das escolas da rede pública no que tange a inserção de estudantes oriundos de meios iletrados à prática de leitura.

Em vista disso, possibilitar novas oportunidades de prática de leitura do mundo com estudantes nos anos finais da Educação Básica foi/é um desafio na Biblioteca escolar e dentro da sala de aula, porque os sujeitos da pesquisa já carregavam um longo histórico de atividades de leitura maçantes e desconexas (Kleiman, 2008). Não obstante, é necessário repensar a "falha" do PNBE, pois os acervos disponibilizados não são acessados massivamente - como a utilização do discurso da qualidade, sob viés mercantilista e conservador, atua na educação através do neoliberalismo, construindo e/ou consolidando as brechas para não efetivação das políticas educacionais, assim como a utilização do discurso da qualidade para das políticas públicas educacionais -, neste sentido se desenrolará a pesquisa do mestrado em curso.

Mesmo com o leque de Políticas Públicas para fomento à leitura, a formação do leitor não tem se efetivado nos espaços escolares como apontam os estudos de Kleiman (2008), Lajolo (2002), Pereira (2012). Neste sentido, utilizar estratégias metodológicas como Rodas de Leitura em sala de aula podem possibilitar aos estudantes que ainda não têm a leitura como hábito, o estranhamento e desnaturalização de fatos/experiências do cotidiano, exercitando a consciência crítica, e na biblioteca contribui para o aumento do fluxo daqueles que têm a leitura como um hábito colaborando com a efetivação do acesso aos materiais disponibilizados pelo PNBE na tentativa de incitar o exercício da leitura crítica (DELORS, 1998). 


\section{REFERENCIAS}

ABU-EL-HAJ, Mônica F. O que dizem os especialistas sobre o ensino e a formação do leitor no contexto escolar. In: A formação do leitor na escola pública: discursos, práticas e percursos de leitura / Organizadores, Mônica Faris Abu-El-Haj ... [et at.]. - Teresina: EDUFPI, 2013.

ANDRÉ, Marli E. D. A. de. Etnografia da prática escolar. Campinas: Papirus, 2008.

BRAGA, Regina M.; SILVESTRE, Maria de F. B. Construindo o leitor competente: atividades de leitura interativa para a sala de aula. São Paulo: Petrópolis. 2002.

BRASIL. Brasil no PISA 2015: análises e reflexões sobre o desempenho dos estudantes brasileiros / OCDE-Organização para a Cooperação e Desenvolvimento Econômico. São Paulo : Fundação Santillana, 2016. Disponível:

<http://download.inep.gov.br/aAcoes_internacionais/pisa/resultados/2015/pisa2015_completo _final_baixa.pdf>. Acesso em: 25.fev.2018.

. Ministério da Educação (MEC). Módulo Programas do Livro-PLi / Fundo Nacional de Desenvolvimento da Educação. Secretaria de Educação à Distância. Brasília: MEC, FNDE, SEED, 2008.

Programa Nacional Biblioteca da Escola. Disponível em:

$<$ http://portal.mec.gov.br/index.php?option=com_content\&view=article\&id=12368:programa -nacional-bibliotecada-escola\&catid=309:programa-nacional-biblioteca-daescola\&Itemid=574>. Acesso em: 02fev2015.

Disponível em:

<http://prolivro.org.br/home/images/2016/Pesquisa_Retratos_da_Leitura_no_Brasil__2015.pdf>. Acesso em: 01abr2016.

Pesquisa Retratos da Leitura no Brasil. $3^{\text {a }}$ EDIÇÃO. 2011. Disponível em: $<$ http://prolivro.org.br/home/images/relatorios_boletins/3_ed_pesquisa_retratos_leitura_IPL.p df >. Acesso em: 30fev2016.

. Pesquisa Retratos da Leitura no Brasil / Instituto Pró-Livro. 2a Edição. 2007. Disponível em: <http://www.abrale.com.br/wp-content/uploads/retratos-leitura-nobrasil.pdf $>$. Acesso em: 30fev2016.

CLAUDE, Richard P. Direito à educação e educação para os direitos humanos. SUR - Revista Internacional de Direitos Humanos. v. 2, p. 36-63, 2005. Ano 2. Disponível em: $\leq$ http://www.scielo.br/scielo.php?pid=S180664452005000100003\&script $=$ sci_arttext $\geq$ Acesso em: 14mar2018.

CUNHA, Carla G. S. da. Avaliação de Políticas Públicas e Programas Governamentais: tendências recentes e experiências no Brasil. 2006. Disponível em: <www.ufpa.br/epdir/images/docs/paper06.pdf >. Acesso em: 12 abr2016

DAYRELL, Juarez. A Escola "faz" as Juventudes? Reflexões em torno da Socialização Juvenil. Educação e Sociedade., Campinas, vol. 28, n. 100 - Especial, p. 1105-1128, out. 
2007. Disponível em: <http://www.scielo.br/pdf/es/v28n100/a2228100>. Acesso em: 05 mai2018.

Delors, Jacques [orgs et all]. Educação: um tesouro a descobrir. Relatório parpara a UNESCO da Comissão Internacional sobre Educação para o século XXI. São Paulo: UNESCO. 1998.

FARENZENA, Nalú, Assistência da União na Educação Básica: referências de políticas de gestão em foco. Políticas Educativas, Porto Alegre, v. 8, n.1. p.51-67, 2014. Disponível em: <https://seer.ufrgs.br/Poled/article/viewFile/56542/34831>. Acesso em: 13mai2018.

GENTILI, Pablo. Neoliberalismo e educação: manual do usuário. In: SILVA, Tomás T. da \& GENTILI, Pablo (Orgs.). Escola S.A.: quem ganha e quem perde no mercado educacional do neoliberalismo. Brasília, DF: CNTE, 1996, p. 9-49.

HÖLFING, E. M. Estado e Políticas (Públicas) Sociais. Cadernos Cedes. Campinas, ano XXI, No. 54, p. 30-41. Nov. 2001. Disponível em:

<http://www.scielo.br/pdf/ccedes/v21n55/5539.pdf>. Acesso em: 10jun2017.

hooks, beel. Ensinando a transgredir: a educação como prática da liberdade. Tradução de marcelo Brandão Cipolla. São Paulo: Editora WMF Martins Fontes, 2013.

HORELLOU-LAFARGE, Chantal; SEGRÉ, Monique. Sociologia da leitura. Tradução de Mauro Gama. Cotia: Ateliê Editorial, 2010.

KLEIMAN, Angela B. Oficina de leitura: teoria \& prática. Campinas: Pontes, 2008.

LAJOLO, Marisa. Do mundo da leitura para a leitura do mundo. São Paulo: Editora Ática, 2002.

MAUÉS, Flamarion. A exclusão da leitura. Revista Teoria e Debate. São Paulo, n. 50, fev./mar./abr. 2002. Disponível em: <https://teoriaedebate.org.br/2002/03/05/a-exclusao-daleitura/>. Acesso em: 08mar2016.

MERCÊS, Darlaine Pereira Bomfim das. A FORMAÇÃO DO SUJEITO LEITOR: as Políticas Públicas de incentivo à leitura e a utilização da Biblioteca no Colégio Estadual Governador Roberto Santos. Trabalho de Conclusão de Curso (graduação). Universidade do Estado da Bahia. Departamento de Educação - Campus I. Salvador, 2016.

OLIVEIRA, Adriano M.; TOMAZETTI, Elisete M. Novos sujeitos do ensino médio? Reflexões acerca da subjetivação juvenil no cenário escolar contemporâneo. Acta

Scientiarum. Education. v.32, n.1. p. 127-134. 2010. Disponível em: <http://periodicos.uem.br/ojs/index.php/ActaSciEduc/article/view/10346/10346>. Acesso em: 09abr2018.

OLIVEIRA, Romualdo P. O Direito à Educação. In. OLIVEIRA, Romualdo. P. \& ADRIÃO, Theresa. Gestão Financiamento e Direito à Educação. 3. ed. São Paulo, Xamã, 2017. P. 1541 
PEREIRA, Cleibiane A. A importância da leitura no Ensino Médio para formação de alunos críticos, 2012. Monografia (Graduação). Universidade Estadual de Goiás, Jussara, 2012. Disponível em: 〈〉. Acesso em:

SILVA, Ezequiel T. da. Leitura na escola e na biblioteca. $8^{\text {a }}$ ed. Campinas: Papirus. 2003.

SOUZA, Celina. Políticas Públicas: uma revisão da literatura. Sociologias. Porto Alegre, ano 8, n.16, jul/dez, 2006. Disponível em: <http://www.scielo.br/scielo.php?script=sci_arttext\&pid=S1517-

45222006000200003\&lng=pt\&nrm=iso\&userID=-2> Acesso em: 02nov2015.

TORRES, Carlos A. Teoria Crítica e Sociológica. São Paulo: Cortez, 2003. 